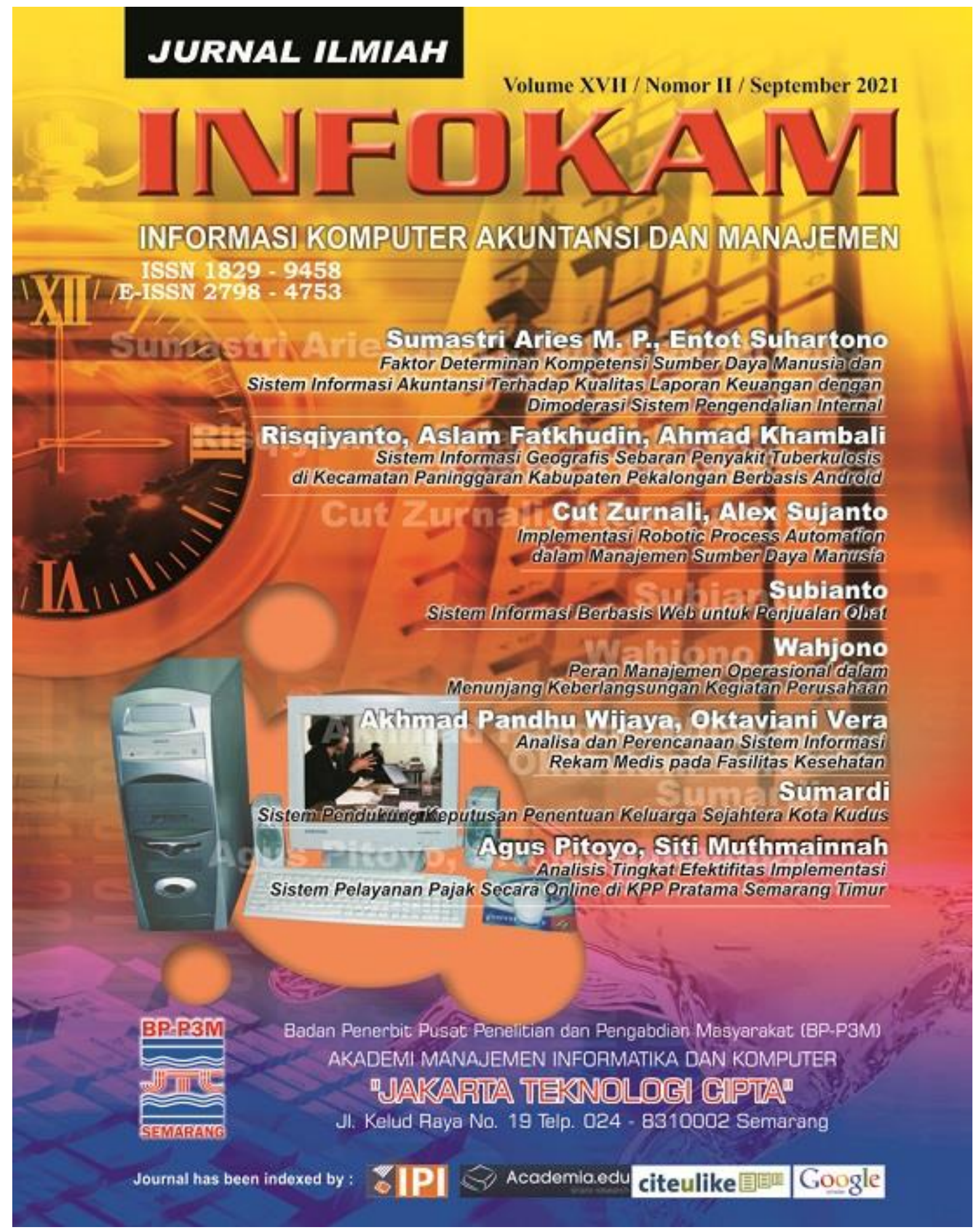


INFORMASI KOMPUTER AKUNTANSI DAN MANAJEMEN

ISSN 1829 - 9458

E-ISSN 2798 - 4753

SK DIREKTUR AMIK "JTC" SEMARANG

NO. 6305/AMIKJTC/D/IX/2020

Penasehat : Dr. Alex Sujanto, SE, S.Pd, MM. (Direktur)

Pengarah : Kristiawan Nugroho, M.Kom (Pudir I)

Muhamad Danuri, M.Kom (Pudir III)

Penanggung Jawab : Sumardi, S.Kom, M.Kom (Ka Progdi KA)

Subianto, S.Kom, M.Kom (Ka.Progdi MI)

Ketua Dewan Redaksi

Wahjono, SE, M.Si (Ketua Editor)

Sekretaris Editor

Anton Sujarwo, M.Si

Bendahara

Agus Pitoyo, M.Si

Anggota Dewan Editor

Subianto, M.Kom

Sumardi, M.Kom

Dr. Heru Sulistyo, SE, MSI ( STIE Dharmaputra Semarang)

Agus Prasetyo Utomo, MM., M.Kom (Univ. Stikubank Semarang)

Ira Setiawati, SE, M.Si (Univ. PGRI Semarang)

Eko Riyanto, S.Pd, M.Kom (STMIK Himsya Semarang)

Editor Teknis Dan Pelaksana

Sugeng Murdowo, S.T, S.Kom, M.Kom

Dr. Alex Sujanto, SE, S.Pd, MM

Mitra Bestari Peer Reviewer

Komputer

Daniel Alfa Puryanto, M.Kom (STMIK AKI Pati)

Aslam Fathkudin, M.Kom (Univ. Muh. Pekajangan Pekalongan)

Entot Suhartono, M.Kom (Univ. Dian Nuswantoro)

Fata Nida'ul Khasanah, M.Eng (Univ. Bhayangkara Jakarta Raya)

Noor Azizah, S.Kom, M.Kom (Univ. Islam Nahdatul Ulama Jepara)

\section{Akuntansi}

Dr. Heru Sulistiyo, M.Si, Akt (STIE Dharmaputra Semarang)

Arini Novandalina, M.Si (STIE Semarang)

Manajemen

Prof. Dr. Amron, SE. MM (Univ. Dian Nuswantoro Semarang)

Entot Suhartono, M. Kom (Univ. Dian Nuswantoro Semarang)

\section{Section Editor}

Subianto, S.Kom, M.Kom

Jurnal Ilmiah INFOKAM terbit minimal setiap 6 bulan sekali $(2 \mathrm{X}$ dalam setahun, bulan Maret \& September ) oleh AMIK "JTC" Semarang dengan maksud sebagai media informasi tentang Komputer, Akuntansi dan Manajemen bagi Sivitas Akademika pada khususnya dan masyarakat pada umumnya.

Alamat Redaksi / Penerbit :

Badan Penerbit Pusat Penelitian dan Pengabdian Masyarakat (BP-P3M)

AKADEMI MANAJEMEN INFORMATIKA DAN KOMPUTER

"JAKARTA TEKNOLOGI CIPTA"

Jl. Kelud Raya No. 19 Telp. 024 - 8310002 Semarang www.amikjtc.com/jurnal, email : infokam.amikjtc@gmail.com 


\section{INFORMASI KOMPUTER AKUNTANSI DAN MANAJEMEN \\ ISSN 1829 - 9458 \\ E-ISSN 2798 - 4753}

\section{DAFTAR ISI}

Faktor Determinan Kompetensi Sumber Daya Manusia dan Sistem Informasi Akuntansi Terhadap Kualitas Laporan Keuangan dengan Dimoderasi Sistem Pengendalian Internal

Sumastri Aries M. P., Entot Suhartono

Sistem Informasi Geografis Sebaran Penyakit Tuberkulosis di Kecamatan Paninggaran Kabupaten Pekalongan Berbasis Android

Risqiyanto, Aslam Fatkhudin, Ahmad Khambali

Implementasi Robotic Process Automation Dalam Manajemen Sumber Daya Manusia

Cut Zurnali, Alex Sujanto

Sistem Informasi Berbasis Web untuk Penjualan Obat

Subianto

Peran Manajemen Operasional dalam Menunjang Keberlangsungan Kegiatan Perusahaan

Wahjono

Analisa dan Perencanaan Sistem Informasi Rekam Medis pada Fasilitas Kesehatan

Akhmad Pandhu Wijaya, Oktaviani Vera

Sistem Pendukung Keputusan Penentuan Keluarga Sejahtera Kota Kudus Sumardi

Analisis Tingkat Efektifitas Implementasi Sistem Pelayanan Pajak Secara Online di KPP Pratama Semarang Timur Agus Pitoyo, Siti Muthmainnah 


\title{
Implementasi Robotic Process Automation Dalam Manajemen Sumber Daya Manusia
}

\author{
Cut Zurnali ${ }^{1}$, Alex Sujanto ${ }^{2}$ \\ ${ }^{1}$ Dosen Magister Manajemen Universitas Budi Luhur Jakarta \\ ${ }^{2}$ AMIK Jakarta Teknologi Cipta Semarang
}

\begin{abstract}
Abstrak
Saat ini banyak organisasi atau perusahaan yang menyelaraskan aktivitas operasi mereka dengan kemajuan teknologi informasi. Implementasi teknologi informasi ini memberikan banyak kemudahan, penghematan waktu, dan penurunan biaya. Robotic Process Automation (RPA) adalah perangkat lunak yang didalamnya tertanam teknologi yang memanfaatkan robot perangkat lunak untuk menggantikan kegiatan manusia dalam melakukan tugas administratif. Perangkat lunak RPA terintegrasi dengan fungsi dan alat yang ada untuk menangani tugas-tugas dasar melalui otomatisasi sehingga dapat mengurangi konsumsi waktu, beban biaya pada proses, dan menyelesaikan tugas individu. RPA ini dapat diterapkan dalam aktivitas organisasi atau perusahaan yang memiliki sifat berulang, rawan kesalahan, berbasis aturan, melibatkan data digital, dan memiliki waktu kritis dan musiman serta memerlukan memrosesan data yang banyak. Dalam aktivitas fungsi-fungsi MSDM, RPA dinilai sebagai sebuah solusi yang layak diimplementasikan.

Kata kunci: Robotic Process Automation (RPA)
\end{abstract}

\begin{abstract}
Currently, many organizations or companies are aligning their operating activities with advances in information technology. The implementation of this information technology provides a lot of convenience, saves time, and reduces costs. Robotic Process Automation (RPA) is software that includes embedded technology that utilizes software robots to replace human activities in performing administrative tasks. RPA software integrates with existing functions and tools to handle basic tasks through automation so as to reduce time consumption, cost burdens on processes, and complete individual tasks. This RPA can be applied in organizational or corporate activities that are repetitive, error-prone, rule-based, involve digital data, and are time-critical and seasonal and require processing large amounts of data. In the activities of HRM functions, RPA is considered as a feasible solution to be implemented.
\end{abstract}

Keywords: Robotic Process Automation (RPA)

\section{Pendahuluan}

Robotic Process Automation (RPA) atau Otomatisasi Proses Robotika adalah salah satu teknologi baru yang telah sepenuhnya merevolusi cara organisasi atau perusahaan melihat tugas rutin dan berulang. Dalam website Deloitte, sebuah perusahaan konsultan global yang telah berdiri lebih dari 150 tahun yang lalu, ditampilkan hasil survei terhadap lebih dari 100 pimpinan shared services yang menegaskan bahwa RPA sebagai solusi yang layak dan terbukti.

Shared services (layanan bersama) adalah konsolidasi operasi bisnis yang digunakan oleh banyak bagian dari organisasi atau perusahaan yang sama. Saat ini, sebagian besar perusahaan menggunakan model shared services untuk keuangan, manajemen sumber daya manusia (MSDM) dan teknologi informasi (TI). Hasil survei Deloitte menunjukkan 74 persen responden survei berencana untuk menginvestigasi teknologi ini dan 22 persen telah mengujicoba atau mengimplementasikan sepenuhnya RPA dalam perusahaan..

Dalam area MSDM, mengotomatiskan tugas administratif dan operasional sumber daya manusia (SDM) pada sebuah perusahaan dapat membebaskan banyak waktu dan sumber daya yang dapat digunakan untuk kegiatan yang lebih produktif dan strategis seperti memberikan waktu tatap muka kepada karyawan atau menyelesaikan masalah. RPA adalah cara terbaik untuk mendorong peningkatan kemampuan manajemen data untuk SDM. RPA 
adalah bot perangkat lunak yang mengotomatiskan proses berbasis aturan dan sangat transaksional di departemen SDM yang memerlukan sedikit atau tanpa campur tangan manusia.

RPA dalam aktivitas operasi SDM terutama bekerja dengan meminta robot perangkat lunak (software) ini melakukan tugas operasional berulang yang bervolume tinggi dari karyawan SDM. Ini termasuk tugas-tugas seperti penerimaan karyawan baru, pemrosesan penggajian, registrasi tunjangan, dan pelaporan kepatuhan yang memerlukan sejumlah besar tenaga kerja manual dan berulang. Terlepas dari peningkatan akurasi dan kecepatan pemrosesan data, RPA dapat berperan dalam menurunkan biaya terkait SDM secara keseluruhan. Ini merupakan tugas penting bagi MSDM.

Menurut Mondy and Martocchio (2016), MSDM adalah penggunaan individu untuk mencapai tujuan organisasi. Secara mendasar, semua manajer menyelesaikan sesuatu melalui upaya orang lain. Konsekuensinya adalah manajer di setiap level harus memperhatikan MSDM. Orang-orang yang berurusan dengan masalah SDM menghadapi banyak tantangan, mulai dari tenaga kerja yang terus berubah hingga peraturan pemerintah yang selalu ada, revolusi teknologi, dan ekonomi global. Selain itu, persaingan global telah memaksa organisasi besar dan kecil untuk lebih sadar akan biaya dan produktivitas. Karena sifat kritis dari masalah SDM, hal-hal tersebut harus mendapat perhatian utama dari top management.

Mondy and Martocchio (2016), menyatakan terdapat 6 fungsi MSDM yang ada dalam suatu organisasi atau perusahaan, yaitu:

1) Staffing (Penstafan)

2) Performance Management (Manajemen kinerja)

3) Human Resource Development (Pengembangan sumber daya manusia)

4) Compensation (Kompensasi)

5) Employee and Labor Relations (Hubungan Karyawan dan Tenaga Kerja)

6) Safety and Health (Keselamatan dan kesehatan).

Keenam fungsi MSDM ini akan dijadikan pembahasan dalam tulisan ini namun terlebih dahulu dijelaskan apa itu RPA dan bagaimana peran RPA dalam SDM Perusahaan.

\section{a. Robotic Process Automation}

Saat ini smartphone sudah menjadi barang kebutuhan sehari-hari. Internet hampir menguasai dunia. Kemajuan teknologi mendorong kita melalui hal-hal yang bahkan tidak pernah terpikirkan sebelumnya oleh sebuah revolusi. Lalu kemudian, muncullah sebuah revolusi teknologi baru yang dikenal sebagai: Revolusi Robotika. Apa itu revolusi robotika? Untuk menjawabnya kita harus mengetahui apa itu robot dan teknologi baru yang menyertainya, yang berdampak pada kehidupan kita dan kehidupan generasi masa depan.

Menurut Suswaram dan Sekhara (2021), robotika adalah ilmu desain, konstruksi, dan operasi. Robot memiliki sensor input, kontrol atas kontrol pengambilan keputusan, dan efektor untuk output. Tapi tetap saja dibutuhkan waktu bertahun-tahun untuk meningkatkan kinerjanya. Tujuan utama robot adalah merancang mesin cerdas yang dapat membantu mengurangi tenaga manusia dalam pekerjaan yang berulang. Lebih lanjut, Suswaram dan Sekhara (2021) mengemukakan bahwa kata robot diperkenalkan pertama kali oleh seorang novelis asal Ceko yang bernama Karel Capek. Ia menggunakan kata ini dalam naskah dramanya pada tahun 1920 yang berjudul Rassum's Universal Robots. Dalam bahasa Ceko, kata robot ini biasanya berarti pekerja atau pelayan.

Santos dan Vasconcelos (2020) menyebutkan revolusi robot terus meningkat. Setelah revolusi yang diciptakan oleh Customer Relationship Management (CRM) dan Enterprise Resource Planning (ERP), muncul revolusi di tempat kerja yang disebut: Robotic Process Automation (RPA). Jenis otomatisasi ini bertujuan untuk mengotomatisasi proses bisnis dengan tujuan meningkatkan efisiensi sekaligus memangkas, dengan mengurangi waktu yang dihabiskan manusia untuk berurusan dengan sistem informasi (SI), melakukan tugas yang berulang, seperti mengetik, mengekstraksi, menangani, dan memindahkan data dalam jumlah besar dari satu sistem ke sistem lain, artinya tugas-tugas terstruktur dan manual ini dapat dilakukan oleh robot, sehingga para pekerja dapat mendedikasikan waktu dan upaya mereka untuk tugas-tugas yang menambah nilai.

Robot melakukan tugas berulang dengan menggunakan adaptor Graphical User Interface (GUI) daripada Application Programming Interfaces (APIs) (Cewe et al., 2017 dalam Santos dan Vasconcelos, 2020), tanpa mengubah infrastruktur teknologi informasi (TI) (Mindfields, 2015 dalam Santos dan Vasconcelos, 2020), yang berarti bahwa robot 
melakukan tugas berulang yang biasa dilakukan oleh manusia dengan lebih cepat dan hemat biaya..

Lalu, apa itu RPA? Menurut Balasundaram dan Venkatagiri (2019), kata "robot" memunculkan gambaran film fiksi ilmiah tentang robot seperti dalam film "Star Wars", atau "I, Robot". Namun, RPA memiliki sedikit kesamaan dengan robot perangkat keras. "Robotic (Robotika)" yang diterapkan di sini mengacu pada tugas yang dapat dilakukan secara mekanis, monoton, atau rutin. Robot yang dimaksud di sini adalah program perangkat lunak. "Proses" mengacu pada serangkaian langkah dalam proses bisnis yang dapat diulang, dan karenanya program komputer dapat menjalankan serangkaian langkah ini secara mekanis. "Otomasi" berarti robot perangkat lunak atau "bot" yang menjalankan proses secara otomatis.

Menurut Nawaz (2019), RPA adalah perangkat lunak yang tertanam teknologi yang memanfaatkan robot untuk menggantikan kegiatan manusia untuk melakukan tugas administratif. Perangkat lunak RPA terintegrasi dengan fungsi dan alat yang ada untuk menangani tugas-tugas dasar melalui otomatisasi dan dengan demikian mengurangi konsumsi waktu, beban biaya pada proses, dan menyelesaikan tugas individu. Lebih lanjut ia menjelaskan RPA adalah teknologi baru yang muncul dalam industri rekrutmen dan yang akan membantu berbagai industri maju dan bersaing untuk tetap berada di puncak permainan bisnis mereka.

\section{b. Robotic Process Automation dalam Sumber Daya Manusia Perusahaan}

Anusha N D, et.al. (2019) mengemukakan RPA adalah solusi di mana sebuah 'robot' dapat mengambil alih aktivitas standar dan berulang yang saat ini dilakukan oleh manusia. RPA bukan mesin fisik. Ini adalah perangkat lunak yang bertindak sebagai $a$ virtual (co-) worker virtual (pekerja atau pembantu pekerja virtual) dalam mendukung proses. Perangkat lunak robot membantu dengan tugas-tugas dasar dan dengan demikian dapat mengurangi waktu dan biaya yang dihabiskan untuk proses. Robot RPA adalah perangkat lunak yang tidak menggantikan perangkat lunak SDM atau penggajian ( $H R$ or Payroll software) yang ada. Sebuah program yang dapat mengambil alih tugas yang dilakukan oleh manusia. Sangat berguna dalam mendukung proses yang digerakkan oleh data. Keuntungan besar dari RPA adalah robot dapat menggunakan sistem dan proses yang ada. Oleh karena itu tidak diperlukan investasi yang signifikan dalam penggantian sistem SDM.

Menurut Nawaz (2019), sebagian besar departemen SDM dari bisnis mana pun bertanggung jawab atas banyak tugas sepanjang proses perekrutan karyawan hingga pensiun, dalam hal ini ada banyak kegiatan yang berulang, efisiensi, keterlibatan pelamar, pengalaman pelamar, memakan waktu dan beberapa pekerjaan masih bergantung pada proses berbasis manual untuk membantu karyawan menyelesaikan pekerjaan mereka. Proses ini tergantung pada tenaga kerja yang prosesnya mahal dan tidak produktif dan terkadang akan mengarah pada tingkat kesalahan yang lebih tinggi dan bahkan membahayakan tingkat kepatuhan.

Anusha N D, et.al. (2019) menegaskan bahwa robot sangat membantu dalam proses yang membutuhkan banyak pemrosesan data. Tugas umum untuk robot meliputi: mengumpulkan data dari file atau sistem XLS, menjalankan laporan, menyalin data, memeriksa kelengkapan data, membaca, memproses, mengirimkan email, memasukkan data dalam sistem SDM, dan mengisi formulir sebelumnya. Otomatisasi membuat daftar periksa SDM perusahaan (Human Resource checklist) jauh lebih pendek. Daripada harus memperbarui sistem pelacakan pelamar secara manual setelah perekrutan baru, membuat catatan karyawan baru untuk database karyawan perusahaan, mengumpulkan dokumentasi karyawan, dan membuat karyawan baru di sistem penggajian perusahaan, RPA dapat bertindak atas nama anda atau perusahaan untuk menyelesaikan tugas-tugas ini di sistem lain. Ini memungkinkan sistem perangkat lunak anda untuk berkomunikasi satu sama lain. Dengan integrasi RPA, sistem-sistem ini dapat langsung responsif sejak karyawan baru diterima di perusahaan.

Dalam operasi SDM, RPA tidak berarti bahwa robot membuat keputusan. Justru sebaliknya. Kasus penggunaan RPA dalam SDM melibatkan otomatisasi tindakan administratif dan klerikal yang paling sederhana dan berulang di tingkat penekanan tombol. Proses operasi SDM yang dapat disederhanakan dengan menggunakan RPA meliputi 
hubungan karyawan, pelatihan dan pengembangan, perekrutan (recruiting) dan mempekerjakan (hiring), tunjangan dan kompensasi, dan aktivitas generalis (ahli) SDM.

Balasundaram dan Venkatagiri (2019) mengungkapkan inovasi teknologi seperti cloud computing, internet of things, big data, augmented reality, autonomous robots, cyber security, additive manufacturing, simulation - mengubah industri lanskap (the industrial landscape). Pergeseran ini merupakan pengubah permainan bagi tenaga kerja di seluruh dunia. Peran pekerja manusia sedang diubah secara signifikan dan tidak dapat diubah. Ekonomi dan industri bergerak dari tenaga kerja yang diorganisir di sekitar tenaga kerja manual ke yang diorganisir di sekitar pengetahuan.

Selanjutnya, Balasundaram dan Venkatagiri (2019) menambahkan, meskipun ada banyak hype (promosi pekerjaan yang sensasional) di seputar Industri 4.0, ada indikasi jelas bahwa kita akan mengalami evolusi pekerjaan yang cepat seperti yang kita kenal. Banyak penelitian menyatakan dan dampaknya sudah terlihat, sebagian besar pekerjaan dengan keterampilan rendah yang ada saat ini dan dibangun untuk melaksanakan tugastugas rutin kemungkinan besar akan hilang. Di sisi lain, pekerjaan baru akan muncul, yang belum pernah ada sebelumnya. Perubahannya begitu dramatis sehingga penelitian oleh World Economic Forum menunjukkan bahwa hampir 70 juta pekerjaan diperkirakan akan tergusur sebagai akibat dari perubahan yang dibawa oleh Industri 4.0. Laporan lain oleh McKinsey (2) menyatakan bahwa pada tahun 2020, dunia kemungkinan akan menghadapi surplus 90 juta pekerjaan dengan keterampilan rendah dan kekurangan sekitar 38 hingga 40 juta pekerjaan.

Menurut Suswaram dan Sekhara (2021), masih diragukan bahwa robotika dalam SDM dapat mengurangi tenaga kerja di industri dengan menggantikan teknologi yang sangat cerdas (highly intelligent technology). Domain SDM memiliki banyak aktivitas transaksional yang cocok untuk proses robotika. Organisasi dapat mengkomputerisasi tugas SDM yang berbasis aturan, berulang dan terstandarisasi dan sebagai hasilnya membebaskan karyawan untuk fokus pada area lain seperti implementasi kebijakan, pengembangan strategi, pengembangan bakat, dan retensi. Menurut laporan Deloitte (dalam Suswaram dan Sekhara, 2021), 42\% karyawan di organisasi telah berpartisipasi aktif dalam survei Global Human Capital Trends yang melaporkan bahwa mereka telah sepenuhnya menerapkan atau membuat kemajuan besar dalam mengadopsi robotika dalam tenaga kerja mereka. Dalam laporan lain tentang layanan bersama global, $45 \%$ karyawan SDM telah mengungkapkan keyakinan mereka bahwa penerapan robotika akan menghasilkan penghematan $10 \%$ hingga $20 \%$ untuk bisnis mereka. ( $A$ report on Robotic Process Automation in Human Resource oleh Bernard Marr, 2018). Penggabungan ini kini telah membuka peluang bagi pengembang TI untuk membuat bot perangkat lunak untuk mengelola pekerjaan yang berulang dan berbasis tugas.

Untuk mempertajam tulisan ini, penulis menilai penting untuk mengunjungi website Deloitte, dimana dalam pembahasan tentang RPA, Deloitte menyatakan:

"Robotic Process Automation (RPA) tools can help HR divisions improve the efficiency and effectiveness of their operations to operate faster and at a lower cost than other automation approaches. Interest and activity in RPA is growing and we are increasingly seeing deployments reaching enterprise scale and operating on processes in the HR function and across the organization".

Pernyataan ini dapat diartikan bahwa keberadaan RPA dapat membantu divisi SDM meningkatkan efisiensi dan efektivitas operasi mereka untuk beroperasi lebih cepat dan dengan biaya lebih rendah daripada pendekatan otomatisasi lainnya. Minat dan aktivitas di RPA tumbuh dan kami semakin melihat penerapan yang mencapai skala perusahaan dan beroperasi pada proses dalam fungsi SDM dan di seluruh organisasi.

Lebih lanjut dalam situs Delloite tersebut dijelaskan bahwa RPA menggunakan perangkat lunak, umumnya dikenal sebagai 'robot', untuk menangkap dan menafsirkan aplikasi TI yang ada untuk memungkinkan pemrosesan transaksi, manipulasi data, dan komunikasi di berbagai sistem TI dalam fungsi back office seperti keuangan, operasi, atau SDM. Beberapa robot dapat dilihat sebagai tenaga kerja virtual - pusat pemrosesan backoffice tetapi tanpa SDM. Ada manfaat finansial karena biaya lisensi robot yang lebih rendah dibandingkan dengan gaji biasa, dan perusahaan juga melihat manfaat non-finansial termasuk peningkatan akurasi, ketepatan waktu, dan fleksibilitas operasional. 
Deloitte sendiri mengakui telah menerapkan perangkat lunak RPA, dalam skala (setara dengan upaya manual 100-an orang), di dalam organisasi klien mereka, dan dalam proses dukungan internal mereka sendiri, misalnya, untuk proses SDM. Mereka merasa berguna untuk mempertimbangkan robotika (dan alat kognitif terkait) dalam hal apa yang sebenarnya dapat mereka lakukan untuk bisnis.

Lalu bagaimana implementasi RPA dalam proses SDM ? Deloitte menjelaskan alat RPA ( $R P A$ tools) adalah paling cocok untuk proses dengan interaksi berulang dan dapat diprediksi dengan aplikasi TI. Proses-proses ini biasanya tidak memiliki skala atau nilai untuk menjamin otomatisasi melalui transformasi sistem inti atau jika transformasi sistem inti tidak segera diimplementasikan. Alat RPA dapat meningkatkan efisiensi proses ini dan efektivitas layanan tanpa mengubah sistem yang digarisbawahi.

'Robot' perangkat lunak RPA ini menurut Delloite dapat melakukan proses bisnis rutin dengan meniru cara orang berinteraksi dengan aplikasi melalui antarmuka pengguna dan mengikuti aturan sederhana untuk membuat keputusan. Seluruh proses ujung ke ujung dapat dilakukan oleh robot perangkat lunak dengan interaksi manusia yang sangat sedikit, biasanya untuk mengelola pengecualian. RPA dapat digunakan untuk mengotomatisasi proses yang:

- Repetitive (berulang-ulang)

- Prone to error (rawan kesalahan)

- Rules based (berbasis aturan)

- Involve digital data (Melibatkan data digital)

- Time critical and seasonal (Waktu kritis dan musiman)

Sebagai tambahan, penulis menilai RPA juga dapat menciptakan Green Human Resource Management, dikarenakan RPA dapat meminimalisasi aktivitas MSDM yang dapat merusak kelestarian lingkungan dan alam. Menurut Zurnali dan Sujanto (2020) bahwa terdapat empat praktik MSDM yang dapat diterapkan Green Human Resource Management, yaitu: rekrutmen dan seleksi, analisis dan desain pekerjaan, pelatihan dan pengembangan, dan manajemen kinerja yang sifat aktivitasnya berulang. Keempat aktivitas ini selalu berulang sehingga perlu dilakukan dengan aktiitas yang lebih ramah lingkungan. Melalui RPA diyakini bahwa keempat aktivitas MSDM tersebut dapat menciptakan MSDM yang "hijau" atau ramah lingkungan.

\section{Pembahasan}

Tulisan ini mencoba membahas apakah RPA dapat diimplementasikan dalam aktivitas fungsi-fungsi MSDM. Ini dimaksudkan agar dapat memberi kontribusi bagi organisasi atau perusahaan yang ada di Indonesia agar dapat menginvestigasi, mengimplementasikan, dan mengembangkan sistem RPA di Indonesia.

\section{a. Implementasi RPA dalam Penstafan}

Staffing (Penstafan) adalah proses di mana organisasi memastikan telah memiliki jumlah karyawan yang tepat dengan keterampilan yang sesuai dalam pekerjaan yang tepat, pada waktu yang tepat, untuk mencapai tujuan organisasi. Staffing melibatkan analisis pekerjaan, perencanaan SDM, rekrutmen, dan seleksi. Aktivitas staffing ini adalah kegiatan dalam MSDM yang memiliki sifat berulang, rawan kesalahan, berbasis aturan, melibatkan data digital, dan memiliki waktu kritis dan musiman. Sifat aktivitas seperti ini dengan mengacu pada apa yang disampaikan Deloitte dalam websitenya adalah aktivitas yang memungkinkan untuk diterapkan RPA. Disamping itu aktivitas staffing membutuhkan banyak pemrosesan data sehingga diperlukan aktivitas robot untuk menanganinya (Anusha N D, et.al., 2019) dan ini akan menghasilkan aktivitas yang lebih cepat dan hemat biaya

Demikian juga aktivitas penyusunan Job Analysis (Analisis pekerjaan), pengimplementasian RPA sangat memungkin untuk dilakukan. Analisis pekerjaan adalah proses sistematis untuk menentukan keterampilan, tugas, dan pengetahuan yang dibutuhkan untuk melakukan pekerjaan dalam suatu organisasi (Mondy and Martocchio, 2016). Aktivitas analisis pekerjaan berdampak pada hampir setiap aspek MSDM, meliputi perencanaan, rekrutmen, dan seleksi. Pengimplementasian RPA dalam aktivitas-aktivitas yang berulang-ulang ini idealnya dilakukan. 
Kunci utama keberhasilan organisasi atau perusahaan ditentukan dalam penyusunan perencanaan SDM. Perencanaan SDM adalah proses sistematis untuk menyesuaikan pasokan internal dan eksternal orang dengan lowongan pekerjaan yang diantisipasi dalam organisasi selama periode tertentu (Mondy and Martocchio, 2016). Dalam perencanaan SDM data yang diberikan mengatur tahapan untuk perekrutan atau aktivitas SDM lainnya. Aktivitas perencanaan SDM ini juga dapat mengimplementasikan RPA.

Aktivitas lain yang dapat diimplementasikan RPA adalah rekrutmen. Ini sesuai dengan yang dikemukakan Nawaz (2019) bahwa RPA dapat diimplementasikan dalam aktivitas rekrutmen suatu organisasi atau perusahaan. Rekrutmen adalah proses menarik individu secara tepat waktu, dalam jumlah yang memadai, dan dengan kualifikasi yang sesuai untuk melamar pekerjaan di suatu organisasi (Mondy and Martocchio, 2016). Demikian juga dengan aktivitas seleksi, penggunaan RPA dapat memudahkan penyelenggaraannya sekaligus dapat menciptakan aktivitas Green Human Resource. Seleksi adalah proses memilih individu yang paling cocok untuk posisi tertentu dan organisasi dari sekelompok pelamar. Keberhasilan pencapaian fungsi kepegawaian sangat penting jika organisasi ingin secara efektif menyelesaikan misinya. Topik-topik ini secara kolektif sering disebut sebagai kepegawaian (Mondy and Martocchio, 2016).

\section{b. Implementasi RPA dalam Manajemen Kinerja}

Semua organisasi atau perusahaan ingin memiliki kinerja organisasi yang baik. Untuk mencapainya tentunya diperlukan manajemen kinerja yang baik pula. Manajemen kinerja adalah proses berorientasi pada tujuan yang diarahkan untuk memastikan bahwa proses organisasi ada untuk memaksimalkan produktivitas karyawan, tim, dan pada akhirnya, organisasi (Mondy and Martocchio, 2016). Implementasi RPA dalam manajemen kinerja organisasi atau perusahaan dapat membuat kemajuan besar bagi organisasi atau perusahaan.

Penilaian kinerja adalah sistem formal tinjauan dan evaluasi kinerja tugas individu atau tim (Mondy and Martocchio, 2016). Aktivitas penilaian kinerja memiliki sifat berulang, rawan kesalahan, berbasis aturan, melibatkan data digital, dan memiliki waktu kritis dan musiman serta pemrosesan data yang banyak sehingga RPA dapat diimplementasikan untuk hasil penilaian yang lebih cepat dan hemat biaya. Penilaian kinerja dengan implementasi RPA dapat memberi karyawan kesempatan untuk memanfaatkan kekuatan mereka dan mengatasi kekurangan yang teridentifikasi dengan tepat, sehingga membantu mereka menjadi karyawan yang lebih puas dan produktif.

\section{Implementasi RPA dalam Pengembangan Sumber Daya Manusia}

Pengembangan SDM adalah fungsi utama MSDM yang terdiri tidak hanya dari pelatihan dan pengembangan tetapi juga dari kegiatan perencanaan dan pengembangan karir, pengembangan organisasi, dan manajemen dan penilaian kinerja. Sifat pengembangan SDM juga seperti fungsi MSDM yang lain, berulang, rawan kesalahan, berbasis aturan, melibatkan data digital, dan memiliki waktu kritis dan musiman. Pelatihan dirancang untuk memberikan para pembelajar pengetahuan dan keterampilan yang dibutuhkan untuk pekerjaan mereka saat ini. Proses pembelajaran dalam pelatihan yang ditujukan untuk menambah pengetahuan, meningkatkan keahlian, dan memperbaiki sikap atau perilaku akan sangat baik jika menggunakan juga RPA, meskipun ini tidak berarti seluruhnya bisa ditangani oleh Robot RPA. Pengembangan melibatkan pembelajaran yang melampaui pekerjaan saat ini dan memiliki fokus jangka panjang.

Pengembangan SDM memiliki kaitan dengan pengembangan organisasi atau perusahaan. Pengembangan organisasi (PO) adalah upaya terencana dan sistematis untuk mengubah organisasi (budaya perusahaan), biasanya ke lingkungan yang lebih berperilaku (Mondy and Martocchio, 2016). PO berlaku untuk seluruh sistem, seperti perusahaan atau pabrik. Sejumlah metode PO dibahas yang berfungsi untuk meningkatkan kinerja perusahaan.

Salah satu kegiatan PO adalah pengembangan karir. Perencanaan karir adalah proses berkelanjutan dimana seseorang menetapkan tujuan karir dan mengidentifikasi cara untuk mencapainya (Mondy and Martocchio, 2016). Pengembangan karir adalah pendekatan formal yang digunakan oleh organisasi atau perusahaan untuk memastikan bahwa orang dengan kualifikasi dan pengalaman yang tepat tersedia saat dibutuhkan. 
Karier individu dan kebutuhan organisasi tidak terpisah dan berbeda. Organisasi hendaknya membantu karyawan dalam perencanaan karier sehingga kebutuhan keduanya dapat terpenuhi. Kegiatan ini juga memiliki sifat berulang, rawan kesalahan, berbasis aturan, melibatkan data digital, dan memiliki waktu kritis dan musiman dimana memiliki celah untuk pengimplementasian RPA dalam pelaksanaannya secara lebih cepat dan hemat biaya.

\section{d. Implementasi RPA dalam Kompensasi}

Istilah kompensasi mencakup total semua penghargaan (Total Rewards) yang diberikan kepada karyawan sebagai imbalan atas pekerjaan mereka. Menurut Mondy and Martocchio (2016), balas jasa merupakan salah satu atau kombinasi dari berikut ini:

- Kompensasi Keuangan Langsung (Kompensasi Inti): Pembayaran yang diterima seseorang dalam bentuk gaji, gaji, komisi, dan bonus.

- Kompensasi Keuangan Tidak Langsung (tunjangan karyawan): Semua penghargaan finansial yang tidak termasuk dalam kompensasi langsung, seperti liburan berbayar, cuti sakit, liburan, dan asuransi kesehatan.

- Kompensasi Nonfinansial: Kepuasan yang diterima seseorang dari pekerjaan itu sendiri atau dari lingkungan psikologis atau fisik tempat orang tersebut bekerja.

Sifat berulang, rawan kesalahan, berbasis aturan, melibatkan data digital, dan memiliki waktu kritis dan musiman ada dalam aktivitas ini sehingga RPA bisa diimplementasikan. Kegiatan pemberian kompensasi ini juga memerlukan banyak pemroseskan data sehingga sangat tepat untuk pengimplementasian RPA didalam aktivitasnya sebagaimana yang dikemukan oleh oleh Anusha N D, et.al. (2019). Melalui RPA, aktivitas ini dapat dilakukan dengan lebih cepat dan hemat biaya.

\section{e. Implementasi RPA dalam Hubungan Karyawan dan Tenaga Kerja}

Bisnis diwajibkan oleh hukum untuk mengakui serikat pekerja dan melakukan tawar-menawar dengan itikad baik jika karyawan perusahaan ingin serikat tersebut mewakili mereka. Di masa lalu, hubungan ini adalah cara hidup yang diterima oleh banyak pengusaha, tetapi kebanyakan organisasi atau perusahaan saat ini lebih suka memiliki lingkungan bebas serikat pekerja. Ketika serikat pekerja mewakili karyawan perusahaan, aktivitas SDM sering disebut sebagai hubungan kerja, yang menangani pekerjaan perundingan bersama. Hubungan karyawan internal terdiri dari kegiatan MSDM yang terkait dengan pergerakan karyawan dalam organisasi seperti promosi, penurunan pangkat, pemutusan hubungan kerja, dan pengunduran diri. Semua aktivitas ini memiliki sifat berulang, rawan kesalahan, berbasis aturan, melibatkan data digital, dan memiliki waktu kritis dan musiman serta memerlukan pemrosesan data yang banyak sehingga RPA bisa diimplementasikan dalam pelaksanaannya agar lebih cepat dan hemat biaya.

\section{f. Implementasi RPA dalam Keselamatan dan kesehatan}

Keselamatan melibatkan melindungi karyawan dari cedera yang disebabkan oleh kecelakaan terkait pekerjaan. Kesehatan mengacu pada kebebasan karyawan dari penyakit fisik atau emosional. Aspek-aspek pekerjaan ini penting karena karyawan yang bekerja di lingkungan yang aman dan menikmati kesehatan yang baik cenderung lebih produktif dan menghasilkan keuntungan jangka panjang bagi organisasi. Saat ini, peraturan dan undangundang di Indonesia dinilai mencerminkan kepedulian masyarakat sehingga sebagian besar organisasi dan perusahaan telah memperhatikan kebutuhan keselamatan dan kesehatan karyawan mereka.

Aktivitas berkenaan dengan keselamatan dan kesehatan menjadi perhatian khusus karena menyangkut operasi organisasi atau perusahaan. Aktivitas ini juga memiliki sifat berulang, rawan kesalahan, berbasis aturan, melibatkan data digital, dan memiliki waktu kritis dan musiman serta memerlukan memrosesan data yang banyak sehingga RPA bisa diimplementasikan agar lebih cepat dan hemat biaya.

\section{Kesimpulan}

Berdasarkan pembahasan mengenai implementasi RPA dalam fungsi MSDM maka dapatlah dibuat kesimpulan bahwa aktivitas-aktivitas dalam fungsi MSDM, penstafan. manajemen kinerja, pengembangan SDM kompensas, hubungan karyawan dan tenaga kerja, 
dan keselamatan dan kesehatan memiliki sifat berulang, rawan kesalahan, berbasis aturan, melibatkan data digital, dan memiliki waktu kritis dan musiman serta memerlukan pemrosesan data yang banyak. Oleh karena itu aktivitas-aktivitas dalam fungsi MSDM dapat diimplementasikan RPA dalam pelaksanaannya sehingga dapat lebih cepat dan hemat biaya. Sebagai tambahan, RPA juga dinilai dapat mengurangi kerusakan alam dan dilingkungan sehingga implementasi RPA dalam MSDM dapat menciptakan MSDM hijau atau ramah lingkungan.

\section{Daftar Pustaka}

Anusha N D, et.al., 2019, RPA for Human Resource Operations. International Journal of Engineering Research \& Technology (IJERT), Vol. 8 Issue 04, April, ISSN: 2278-0181

Balasundaram, Sathiyaseelan dan Venkatagiri, Sirish, 2019 Structured Approach to Implementing Robotic Process Automation in HR, Journal of Physics: Conference Series, 1427 (2020) 012008, Third National Conference on Computational Intelligence (NCCI 2019)

Mondy, R. Wayne dan Martocchio, Joseph, 2016, Human Resource Management, 14th Edition, Pearson

Nawaz, Nishad, 2019, Robotic Process Automation for Recruitment Process, International Journal of Advanced Research in Engineering and Technology (IJARET), Volume 10, Issue 2, March-April, pp. 608-611

Santos, F., Pereira, R. dan Vasconcelos, J. B., 2020, Towards Robotic Process Automation Implementation: An end-to-end perspective, Business Process Management Journal. 26 (2), 405-420

Suswaram, Sowmya dan Sekhara, S. Chandra, 2021, Study on Role of Robotics in Digilisation of Human Resource Developement: Impact and RPA Implementation, International Journal of Creative Research Thoughts (IJCRT), Volume 9, Issue 3 March 2021 / ISSN: 2320-2882

Zurnali dan Sujanto, 2020, Pentingnya Green Human Resource Management, Jurnal Infokam Vol. XVI, No. 2, AMIK Jakarta Teknologi Cipta, Semarang 